\title{
A case report of Evans Syndrome
}

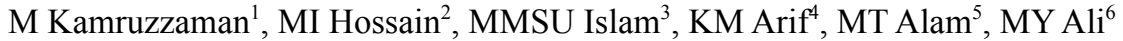

\begin{abstract}
:
Evans syndrome is a haematological disorder characterized by the sequential or simultaneous development of direct antiglobulin test (DAT) positive autoimmune haemolytic anaemia (AIHA), immune thrombocytopenia (ITP) and/or immune neutropenia in the absence of a known aetiology. No sex predilection is known. It may occur in all ethnic groups and all ages. This condition generally runs a chronic course and is characterized by frequent exacerbations and remissions. Here we report a case of a female who presented with both acute decompensated anaemia \& thrombocytopenia. She received total 5 bags blood within 10 days for correction of anaemia but patients condition was deteriorating. $\mathrm{CBC}$ with $\mathrm{PBF}$ showed features consistent with immune haemolytic anaemia with thrombocytopenia, marked roulaeux formation and reticulocytosis. Direct Coomb's test (DAT) was positive and Indirect coomb's test was (IAT) negative. Her general condition was improved after injection methyl prednisolone for 3 days followed by oral prednisolone. Follow up CBC showed increased haemoglobin and platelet count without blood transfusion.
\end{abstract}

Key words: Evans Syndrome, immune thrombocytopenia (ITP), autoimmune haemolytic anaemia (AIHA), direct antiglobulin test (DAT), Indirect antiglobulin test (IAT).

\section{Introduction:}

Evans syndrome is an uncommon condition defined by the combination (either simultaneously or sequentially) of direct antiglobulin test positive autoimmune haemolytic anaemia (AIHA), immune thrombocytopenia (ITP) and/or immune neutropenia in the absence of a known underlying aetiology. There is evidence to support abnormalities in both cellular and

1. Dr. Muhammad Kamruzzaman, MBBS, FCPS (Haematology), Assistant Professor of Haematology, Faridpur Medical College, Faridpur.

2. Dr. Mohammad Iqbal Hossain, MBBS, FCPS (Medicine), Assistant Professor, Department of Medicine, Faridpur Medical College, Faridpur.

3.Dr. M. M. Shahin-Ul-Islam, MBBS, FCPS (Medicine), MD (Gastroenterology), Assistant professor, Department of Gastroenterology, Faridpur Medical College, Faridpur.

4. Dr. Khan Mohammad Arif, MBBS, FCPS (Medicine), Assistant Professor, Department of Medicine, Faridpur Medical College, Faridpur.

5. Dr. Md. Towhid Alam, MBBS, FCPS (Medicine), Associate professor\& Head, Department of Medicine, Faridpur Medical College, Faridpur.

6. Prof. Dr. Md. Yusuf Ali, MBBS, FCPS (Medicine), Professor \& Head, Department of Medicine, Faridpur Diabetic Association Medical College, Faridpur.

\footnotetext{
Address of correspondence :

Dr. Muhammad Kamruzzaman, MBBS, FCPS (Haematology), Assistant Professor of Haematology, Faridpur Medical College, Faridpur. Phone: +88-01716344301,

Email: kamruzzaman.sb29@gmail.com
}

humoral immunity in Evans syndrome ${ }^{1}$. Evans syndrome is a diagnosis of exclusion. This means that a diagnosis is made in people with Coombs positive haemolytic anaemia and thrombocytopenia related to an abnormal immune response once other conditions with similar signs and symptoms have been ruled out. Various blood tests and in some cases, a bone marrow may be needed to exclude other conditions.

\section{Case Report:}

A 48 years old female got admitted into medicine department of Faridpur Medical College Hospital with the complaints of low grade intermittent fever with chill, high color urine and generalized weakness. She had no history of joint pain, oral ulcer, photosensitivity or other systemic symptoms. She was diabetic for 2 years, normotensive, non-asthmatic. She received total 5 bags blood within 10 days for correction of anaemia but her condition was deteriorating. She had a history of total abdominal hysterectomy due to bulky uterus 5 years back. She was found severe anaemic, mild icteric and had bruise on both legs. She had no bony tenderness, any lymphadenopathy or organomegaly. Laboratory findings:

$$
\begin{aligned}
& \checkmark \mathrm{CBC}: \mathrm{ESR}=140 \mathrm{~mm}, \mathrm{RBC}=1.31 \text { million, Hct= } \\
& 13.8 \%, \quad \mathrm{Hb}=4.2 \mathrm{gm} / \mathrm{dl}, \quad \mathrm{MCV}=105.3 \mathrm{fL}, \\
& \mathrm{MCH}=32.1 \mathrm{pg}, \mathrm{MCHC}=30.4 \mathrm{gm} / \mathrm{dl}, \quad \mathrm{RDW}- \\
& \mathrm{CV}=27.9 \%, \mathrm{WBC}=14370 / \mathrm{cmm}, \mathrm{N}=75 \%, \mathrm{~L}=21 \%, \\
& \mathrm{M}=02 \%, \mathrm{E}=02 \%, \mathrm{~B}=00 \%, \text { Platelet }=90000 / \mu \mathrm{L} .
\end{aligned}
$$


$\checkmark$ PBF showed features consistent with immune haemolytic anaemia with thrombocytopenia and marked roulaeux formation.

$\checkmark$ Reticulocyte count was about $26 \%$.

$\checkmark$ Direct Coomb's test (DAT) was positive. Indirect coomb's test (IAT) was negative.

$\checkmark$ USG whole abdomen showed absent uterus (Operated) otherwise normal.

$\checkmark$ Urine R/M/E showed Color=straw, Albumin=trace, Sugar $=$ orange, Pus cell $=1-3, \mathrm{RBC}=$ nil.

$\checkmark$ Bone marrow shows Dimorphic erythroid and megakaryocytic hyperplasia.

$\checkmark \mathrm{S}$. Iron $=208.98 \mu \mathrm{gm} / \mathrm{dl}$ (raised); S. Ferritin=443.0 $\mathrm{ngm} / \mathrm{ml}$ (raised); TIBC $=295 \mu \mathrm{gm} / \mathrm{dl}$ (Normal).

$\checkmark$ Serum Bilirubin $=4.4 \mathrm{mg} / \mathrm{dL}$

$\checkmark$ ALT $=44.19 \mathrm{U} / \mathrm{L}$

$\checkmark$ Creatinine $=0.77 \mathrm{mg} / \mathrm{dL}$

$\checkmark \mathrm{RBS}=16.2 \mathrm{mmol} / \mathrm{L}$

$\checkmark \mathrm{TSH}=2.5 \mathrm{mIU} / \mathrm{L}$

$\checkmark$ HBsAg=Negative

$\checkmark$ Anti-HCV=Negative

$\checkmark$ ANA=Negative

Her general condition was improved after Injection Methyl prednisolone $30 \mathrm{mg} / \mathrm{kg} /$ day for 3 days followed by oral prednisolone $1.5 \mathrm{mg} / \mathrm{kg} /$ day continued up to normalization of $\mathrm{CBC}$ then slow tapering. Follow up $\mathrm{CBC}$ after 7 days showed increased haemoglobin and platelet level without blood transfusion. $\mathrm{CBC}$ : $\mathrm{ESR}=115$ $\mathrm{mm}, \mathrm{RBC}=2.41 \mathrm{million}, \mathrm{Hct}=24.0 \%, \mathrm{Hb}=8.0 \mathrm{gm} / \mathrm{dl}$, $\mathrm{MCV}=101.3 \mathrm{fL}, \mathrm{MCH}=33 \mathrm{pg}, \mathrm{MCHC}=33 \mathrm{gm} / \mathrm{dL}, \mathrm{RDW}-$ $\mathrm{CV}=21 \%, \quad \mathrm{WBC}=6000 / \mathrm{cmm}, \quad \mathrm{N}=65 \%, \quad \mathrm{~L}=31 \%$, $\mathrm{M}=02 \%, \mathrm{E}=02 \%, \mathrm{~B}=00 \%$, Platelet $=133000 / \mu \mathrm{L}$.

\section{Discussion:}

Evans syndrome is an uncommon condition defined by the combination (either simultaneously or sequentially) of immune thrombocytopenia (ITP) and autoimmune haemolytic anaemia (AIHA) with a positive direct antiglobulin test (DAT) in the absence of known underlying aetiology. Evans Syndrome was first described by Robert Evans in $1951^{2}$. It is a rare diagnosis and the exact frequency is unknown. No sex predilection is known. It may occur in all ethnic groups and all ages. There is evidence to support abnormalities in both cellular and humoral immunity in Evans syndrome. Both CD4 and CD8 lymphocytes were reduced; increased constitutive production of interleukin-10 and interferon-y caused activation of autoreactive, antibody-producing B cells. Despite the frequency of haemopoietic cell-specific autoantibodies in patients with Evans syndrome, there is very little information about the identity of target antigens.

Patients may present with AIHA or ITP either separately or concomitantly. Neutropenia occurs in up to $55 \%$ of patients at presentation, or pancytopenia $(14 \%)$. The development of the second cytopenia may occur months to years after the first immune cytopenia and may delay diagnosis. Usual features of haemolytic anaemia i.e: pallor, lethargy, jaundice, heart failure in severe cases; and features of thrombocytopenia i.e: petechiae, bruising, mucocutaneous bleeding may be present. The lymphadenopathy and organomegaly (hepatomegaly and/or splenomegaly) may be chronic or intermittent and in some cases may only be apparent during episodes of acute exacerbation ${ }^{2-6}$.

Our patient presented with low grade intermittent fever with chill, high color urine and generalized weakness. She had no history of joint pain, oral ulcer, photosensitivity or other systemic symptoms. She was severe anaemic, mild icteric and had bruise on both legs. She had no bony tenderness, any lymphadenopathy or organomegaly.

Thrombocytopenia has been demonstrated following the measles, mumps and rubella (MMR) vaccination, with the relative risk for ITP within 6 weeks after MMR vaccination ${ }^{7}$. In the case of AIHA, lifethreatening AIHA has been described in a 6-week-old girl, 5 days following her first diptheria-pertussistetanus (DPT) vaccination ${ }^{8}$. AIHA may also develop after the MMR vaccination ${ }^{9}$. The two and following a combination of six vaccines (diptheria, pertussis, tetanus, haemophilus influenzae type B (Hib), polio and hepatitis B] in the other case), thus reflecting a secondary immune response.

A full blood count will confirm the presence of cytopenias and a blood film should be examined for features of AIHA (polychromasia, spherocytes) and to exclude other underlying diagnoses (malignancies, micro angiopathic haemolytic anaemia, congenital haemolytic and thrombocytopenic conditions).

Features of haemolysis should be sought including a raised reticulocyte count, unconjugated hyperbilirubinaemia and decreased haptoglobins. The direct antiglobulin test (DAT) is almost invariably positive (although often weakly so), even in the absence of haemolytic anaemia, and may be positive for $\mathrm{IgG}$ and/or complement $(\mathrm{C} 3)^{3-6}$. The indirect antiglobulin test may also be positive in $52-83 \%$ of patients $^{5,10}$.

Assays for antiplatelet and antigranulocyte antibodies have shown varied results ${ }^{11}$. In a report of 32 adult patients with AIHA, showed antiplatelet antibodies in 91\% (demonstrated by thromboagglutination and indirect antiglobulin consumption tests) and leucocyte antibodies in $81 \%$ (demonstrated by a cytotoxicity test). Common variable immunodeficiency (CVID) and IgA deficiency, which have been reported to develop acquired cytopenias ${ }^{12,13}$, and also as a baseline prior to immunomodulatory therapy. 
In addition, other autoimmune conditions, particularly systemic lupus erythematosis (SLE), should be sought by measuring antinuclear antibody (ANA), doublestranded DNA (dsDNA) and rheumatoid factor. The most important differential diagnosis is Autoimmune lymphoproliferative syndrome (ALPS). Therefore measurement of peripheral blood T-cell subsets by flow cytometry is essential in all cases of Evans syndrome. The presence of double negative $\left(\mathrm{CD}^{-} / \mathrm{CD}^{-}, \mathrm{CD}^{+}\right.$, TCR $\alpha \beta^{+}$) T cells has been found to be the most sensitive first-line screening test for ALPS (and allows differentiation from cases of Evans syndrome) ${ }^{1}$.

Our patient's $\mathrm{CBC}$ showed $\mathrm{ESR}=140 \mathrm{~mm}, \mathrm{RBC}=1.31$ million, Hct $=13.8 \%, \mathrm{Hb}=4.2 \mathrm{gm} / \mathrm{dl}, \mathrm{MCV}=105.3 \mathrm{fL}$, $\mathrm{MCH}=32.1 \mathrm{pg}, \mathrm{MCHC}=30.4 \mathrm{gm} / \mathrm{dl}, \mathrm{RDW}-\mathrm{CV}=27.9 \%$, $\mathrm{WBC}=14370 / \mathrm{cmm}, \mathrm{N}=75 \%, \mathrm{~L}=21 \%, \mathrm{M}=02 \%, \mathrm{E}=02 \%$, $\mathrm{B}=00 \%$, Platelet $=90000 / \mu \mathrm{L}$. PBF consistent with immune haemolytic anaemia, thrombocytopenia and marked roulaeux formation. Reticulocyte count was about 26\%. Direct Coomb's test (DAT) positive. Indirect coomb's test (IAT) negative. USG whole abdomen shows absent uterus (Operated) otherwise normal. Urine R/M/E showed Color=Straw, Albumin=trace, Sugar= orange, Pus cell=1-3, RBC=nil.Bone marrow shows Dimorphic erythroid and megakaryocytic hyperplasia. $\mathrm{S}$. Bilirubin $($ Total $)=4.4 \mathrm{mg} / \mathrm{dL} . \quad \mathrm{ALT}=44.19 \mathrm{U} / \mathrm{L}$. HBsAg negative, Anti-HCV-negative. S. Creatinine $=0.77 \mathrm{mg} / \mathrm{dL}$. RBS $=16.2 \mathrm{mmol} / \mathrm{L}$. ANA was negative. USG whole abdomen shows absent uterus (Operated) otherwise normal.

Evans syndrome is a diagnosis of exclusion and by definition other confounding disorders should not be present $^{2}$. SLE, IgA deficiency, CVID, acquired immunodeficiency syndrome and ALPS. Paroxysmal nocturnal haemoglobinuria (PNH), acquired thrombotic thrombocytopenic purpura, inherited ADAMTS-13 deficiency, haemolytic uraemic syndrome and Kasabach-Merritt syndrome. Secondary to multicentric Castleman's disease, interleukin-2 therapy for renal carcinoma or following autologous or allogeneic stem cell transplantation (SCT).

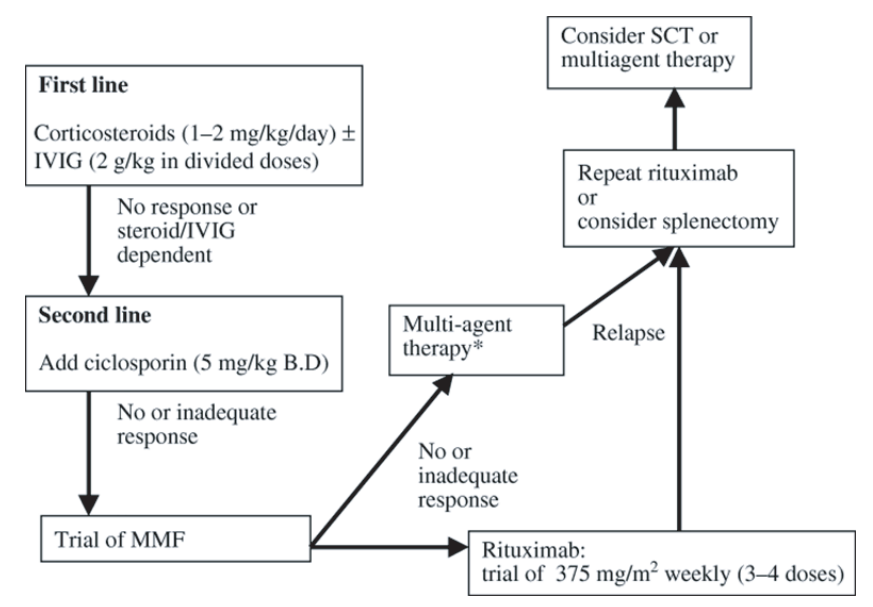

Her general condition was improved after injection methyl prednisolone $30 \mathrm{mg} / \mathrm{kg}$ /day for 3 days followed by oral prednisolone $1.5 \mathrm{mg} / \mathrm{kg} /$ day continue upto normalization of $\mathrm{CBC}$ then slow tapering.

Follow up $\mathrm{CBC}$ after 7 days showed increased haemoglobin level without blood transfusion.CBC: $\mathrm{ESR}=115 \mathrm{~mm}, \mathrm{RBC}=2.41$ million, $\mathrm{Hct}=24.0 \%$, $\mathrm{Hb}=8.0 \mathrm{gm} / \mathrm{dl}, \mathrm{MCV}=101.3 \mathrm{fL}, \mathrm{MCH}=33 \mathrm{pg}, \mathrm{MCHC}=$ $33 \mathrm{gm} / \mathrm{dL}, \mathrm{RDW}-\mathrm{CV}=21 \%, \mathrm{WBC}=6000 / \mathrm{cmm}, \mathrm{N}=65 \%$, $\mathrm{L}=31 \%, \quad \mathrm{M}=02 \%, \quad \mathrm{E}=02 \%, \quad \mathrm{~B}=00 \%, \quad$ Platelet= $133000 / \mu \mathrm{L}$.

In long-term follow-up most authors described more frequent episodes of ITP compared with episodes of AIHA. Causes of death were mainly related to haemorrhage or sepsis and reassuringly, given the degree of immune dysregulation seen in many patients, none of the patients described in these long-term studies (mainly of children) developed malignancy.

At best, the data suggest a role for corticosteroids +/IVIG as first-line therapy in the acute setting, with blood product support as necessary. Second-line therapy, in the form of single agent or, for more severe cases, multi-agent, immunosuppressants will usually be required. A therapeutic trial of ciclosporin as the best second-line option for most patients, with MMF and then multi-agent therapy or rituximab for those that fail to respond.

Splenectomy commonly achieves only short-term responses but may reduce the frequency of relapses and allow reduction of immunosuppressive agents. The choice of splenectomy versus rituximab may be a difficult one and will need to be made on a case-by-case basis.

Finally, high-dose therapy plus stem cell support provides hope for long-term cure in patients with a matched family donor; the success of a reducedintensity conditioning regimen is an encouraging approach for this group of patients who have usually been extensively pretreated and are often in poor clinical condition prior to referral for SCT. Evans syndrome is characterized by recurrent episodes of relapse and remission of both ITP and AIHA. In some patients it seems likely that long-term cure may only be achievable with SCT.

\section{Conclusion:}

Evans syndrome is a very rare autoimmune disorder in which the immune system destroys the body's RBC, WBC and/or platelets. The exact cause of this condition is unknown. The best treatment options for Evans syndrome depend on many factors, including the severity of the condition; the sign and symptoms present; and each person's response to certain therapies. 
However, as with many other rare disorders, progress may depend upon the acquisition of detailed information through national/international databases and international multicentre randomized trials to accrue sufficient numbers of patients; long-term followup is also essential for the chronic relapsing nature of this condition.

\section{References :}

1. Teacheyet DT, Manno CS, Axsom KM, Andrews T, Choi JK Greenbaum BH, et al.Unmasking Evans syndrome: T-cell phenotype and apoptotic response reveal autoimmune lymphoproliferative syndrome (ALPS). Blood 2005; 105 (6):2443-8.

2. Evans RS, Takahashi K, Duane RT. Primary thrombocytopenic purpura and acquired hemolytic anemia. Archives of Internal Medicine 1951; 87:48-65

3. Pui CH, Wilimas J, Wang W. Evans syndrome in childhood. J Pediatr. 1980; 97 (5):754-8.

4. Wang WC. Evans syndrome in childhood: Pathophysiology, clinical course, and treatment. Am J pediatr Hematol Oncol. 1988; 10(4):330-8.

5. Mathew P, Chen G, Wang W. Evans syndrome: results of a national survey. J Pediatr Hemato Oncol. 1997; 19(5):443-7.

6. Savasan S, Warrier I, Ravindronath Y. The spectrum of Evan's syndrome. Archives of Disease in childhood 1997; 77(3): 245-8.

7. Nieminem U, Peltola H, Syrjala MT. Acute thrombocytopenic purpura following measles, mumps and rubella vaccination. A report on 23 patients. Acta Paediatrica 1993; 82:267-70.

8. Johnson ST, McFarland JG, Kelly KJ. Transfusion support with $\mathrm{RBCs}$ from an Mk homozygote in a case of autoimmune hemolytic anemia following diphtheria-pertussis-tetanus vaccination. Transfusion 2002; 42:567-71.

9. Seltsam A, Shukry-Schulz S, Salama A. Vaccination associated immune hemolytic anemia in two children. Transfusion 2000; 40:907-9.

10. Pegels JG, Helmerhorst FM, van Leeuven EF. The Evans syndrome: characterization of the responsible autoantibodies. British Journal of Haematology 1982; 51:445-50.

11. Fagiolo E. Platelet and leukocyte antibodies in autoimmune hemolytic anemia. Acta Haemtologica 1976; 56:97-106.

12. Hansen OP, Srrensen CH, Astrup L. Evans syndrome in $\operatorname{IgA}$ deficiency. Episodic autoimmune haemolytic anaemia and thrombocytopenia during a 10 years observation period. Scandinavian Journal of Haematology 1982; 29:265-70.

13. Sneller MC, Strober W, Einstein E, Jaffe JS, CunninghamRundles C. New insights into common variable immunodeficiency. Annals of Internal Medicine 1993; 118:720-30. 